\title{
A concepção de leitura na formação continuada: revelações no discurso de professores ${ }^{1}$
}

\section{The concept of reading in continuing education: revelations in the discourse of teachers}

\author{
Lauciane Piovesan Zago*
}

\begin{abstract}
RESUMO: A pesquisa aqui apresentada está vinculada ao Observatório da Educação (UNIOESTE/CAPES/INEP) e ao projeto de pesquisa Formação continuada para professores da educação básica nos anos iniciais: ações voltadas para a alfabetização em municípios com baixo IDEB da região Oeste do Paraná, da Universidade Estadual do Oeste do Paraná. Nesse contexto de investigação, voltamo-nos para o tema "leitura", a partir dos princípios teóricos da Linguística Aplicada e da perspectiva sóciohistórica do conhecimento, com o objetivo de compreender como a formação continuada interfere nas ações pedagógicas de leitura de professores de $5^{\circ}$ ano do Ensino Fundamental I. Para isso, desenvolvemos uma pesquisa sustentada na abordagem qualitativa, de base etnográfica, trazendo para a análise dados gerados por meio da entrevista semiestruturada, focalizando as concepções de linguagem/leitura que guiam a ação pedagógica desses docentes. A partir da observação desse corpus, foi possível evidenciar, nos discursos dos professores, marcas de uma concepção interacionista de leitura/linguagem, contudo, atestamos que o trabalho em Língua Portuguesa ainda é fortemente marcado por uma visão estruturalista da língua.
\end{abstract}

PALAVRAS-CHAVE: Formação continuada. Concepção de leitura. Ensino.

ABSTRACT: The research presented here is linked to the Centre of Education (UNIOESTE/CAPES/INEP) and the research project Continuing education for teachers of basic education in the early years: actions to promote literacy in municipalities with low IDEB of the western Paraná, State University of Western Paraná. In this research context, we turn to the theme of "reading" from the theoretical principles of Applied Linguistics and socio-historical knowledge, with the aim of understanding how the ongoing training of pedagogical actions interferes with reading teachers 5 th year of

\footnotetext{
${ }^{1}$ Este trabalho é resultado da pesquisa (financiada pela CAPES/INEP) de mestrado intitulada: $A$ concepção de leitura na formação continuada: implicações no processo de organização da prática pedagógica, desenvolvida no Programa de Pós-graduação Stricto Sensu em Letras, área de concentração em Linguagem e Sociedade, da Universidade Estadual do Oeste do Paraná UNIOESTE -, sob orientação da Profa. Dra. Terezinha da Conceição Costa-Hübes.

* Mestre pelo Programa de Pós-Graduação Stricto Sensu em Letras da Universidade Estadual do Oeste do Paraná - UNIOESTE (Cascavel). Bolsista CAPES. Professora da rede municipal de ensino de Guaraniaçu - Paraná. Especialista em Educação Especial - ISAL. Especialista em Língua Portuguesa pelo ESAP . Graduada em Letras- Português/Inglês- pela Universidade Paranaense (2005) - UNIPAR. Contato: Ihpzlauciane@hotmail.com
} 
elementary school I. For this, we develop a sustained research on the qualitative approach, based on ethnographic research, bringing to analyze data generated through semi-structured interviews, focusing on the concepts of language / reading that guide the pedagogical action of these teachers. From the observation of this corpus was able to evidence in the speeches of teachers, marks an interactionist conception of reading / language, however, testify that the work in LP is still strongly marked by a structuralist view of language.

KEYWORDS: Continuing Education. Conception of reading. Teaching.

\section{Introdução}

No âmbito das políticas públicas, o processo de formação continuada de professores tem ganhado destaque no cenário nacional. Esse crescimento pode ser evidenciado com maior clareza a partir da década de 1990, quando no âmago das reformas educacionais ocorre a implementação da Lei de Diretrizes e Bases da Educação Nacional - LDB 9394 (BRASIL, 1996) - que intensifica a valorização do profissional da educação e institui outras providências. Ganha destaque, na referida lei, o art. 67, que discorre acerca da valorização profissional por meio da Formação Continuada (doravante FC):

\footnotetext{
Art. 67. Os sistemas de ensino promoverão a valorização dos profissionais da educação, assegurando-lhes, inclusive nos termos dos estatutos e dos planos de carreira do magistério público:

I - ingresso exclusivamente por concurso público de provas e títulos;

II - aperfeiçoamento profissional continuado, inclusive com licenciamento periódico remunerado para esse fim;

III - piso salarial profissional;

IV - progressão funcional baseada na titulação ou habilitação, e na avaliação do desempenho;

V - período reservado a estudos, planejamento e avaliação, incluído na carga de trabalho;

VI - condições adequadas de trabalho. (BRASIL, 1996, p. 25).
}

Para o Brasil, a promulgação dessa lei tornou-se marco histórico e, por conseguinte, a FC entra no contexto brasileiro como uma possibilidade de valorização profissional do magistério e de melhoria da qualidade da educação no país. Configurando-se nesse cenário como um órgão governamental voltado às políticas públicas de valorização do magistério, a Secretaria da Educação 
Básica (BRASIL, 2006) cria o Programa Observatório da Educação (doravante OBEDUC) que, em parceria com a CAPES/INEP, lança, em 2010, o Edital 038/2010², com o objetivo de promover a integração entre programas de pósgraduação e a Educação Básica, por meio de pesquisas voltadas à melhoria da qualidade de ensino, considerando dados revelados pelo Instituto Nacional de Estudos e Pesquisas Educacionais (INEP), oriundos especialmente da Prova Brasil.

O Programa de Pós-Graduação em Letras (PPGL) da UNIOESTE, por se identificar com essa proposta, concorre ao edital com o projeto Formação continuada para professores da educação básica nos anos iniciais: ações voltadas para a alfabetização em municípios com baixo IDEB da região Oeste do Paraná, atrelado à linha de pesquisa Linguagem: práticas linguísticas, culturais e de ensino. Após aprovação, instaura-se no programa o Núcleo de Pesquisa do Observatório da Educação, centrado na temática formação continuada, envolvendo sete municípios da região Oeste do Paraná, cujos índices do IDEB se mostraram abaixo de 5,0 na avaliação da Prova Brasil de 2009.

Assim, dentre os municípios contemplados, desenvolvemos nossa pesquisa voltada para um deles, sobre o qual fizemos uma análise interpretativa referente ao processo de FC desenvolvido em 2012, atentando para a concepção de leitura dos professores participantes. Nessa perspectiva, 0 objetivo geral da pesquisa foi traçado no sentido de compreender como a

\footnotetext{
${ }^{2}$ Com intuito de intervir sobre a realidade educacional ora contextualizada como vir ao encontro às necessidades locais evidenciadas por pesquisas científicas já mencionadas, veiculamos a criação de um Núcleo de Pesquisa atrelado ao Programa de Pós-Graduação Stricto Sensu em Letras - Nível de Mestrado e Doutorado - com área de concentração em Linguagem e Sociedade, da Universidade Estadual do Oeste do Paraná - UNIOESTE, a partir da temática FORMAÇÃO CONTINUADA de professores da Educação Básica - anos iniciais, da região Oeste do Paraná, focalizando, especificamente, municípios que apresentaram índices abaixo de 5,0 na avaliação do INEP/SAEB (dados referente ao ano de 2009), estando em conformidade com o solicitado no Edital 038/2010 - CAPES/INEP (Observatório em Educação - Edital 2010). O objetivo deste projeto assenta-se no anseio de implementar um núcleo de pesquisas cujo foco esteja centrado em estudos que valorizem a alfabetização como um processo essencial ao exercício de práticas sociais de leitura, numeramento, oralidade e escrita, de forma que, por meio das ações voltadas às políticas educacionais de cada município e, dentre elas, à formação continuada, promova o sucesso escolar de municípios da região Oeste do Paraná que apresentaram IDEB abaixo de 5,0.
} 
formação continuada interfere nas ações pedagógicas de leitura de professores de $5^{\circ}$ ano do Ensino Fundamental I. A investigação sustentou-se na necessidade de respondermos aos seguintes questionamentos: $A$ formação continuada pode interferir na ação pedagógica? De que forma? E ainda: Quais as implicações da(s) concepção(ões) de leitura dos professores nas ações pedagógicas?

Uma vez consolidada a pesquisa, pretendemos, neste espaço, discutir, primeiramente, os pressupostos teóricos que subsidiaram nossas ações investigavas. Para isso, abordaremos, a princípio, o que compreendemos por FC e, posteriormente, traremos à baila as diferentes concepções de leitura, posicionando-nos em relação a uma delas, que orientou nossas ações no processo de FC. Com base nesses pressupostos, lançaremos um olhar mais específico sobre o discurso dos professores, sujeitos de nossa pesquisa, procurando vasculhar sua concepção de leitura. Para isso, selecionamos, para análise, uma entrevista semiestruturada direcionada a um grupo de quatro professores que atuavam, em 2011, em turmas de $5^{\circ}$ ano do Ensino Fundamental I.

\section{Formação Continuada: Pressupostos Teóricos Orientadores}

Entendendo que a formação docente em serviço no Brasil possui uma trajetória histórica e socioepistemológica marcada por diferentes abordagens teóricas (treinamento, aperfeiçoamento, reciclagem, capacitação) que não se constituíram a priori, mas que vêm emergindo das diferentes concepções de educação e sociedade presentes nos diferentes contextos da realidade brasileira (PIMENTA, 2005), coube-nos, nesse espaço, esclarecer o entendimento que possuímos e defendemos acerca da formação continuada. Para tanto, corroboramos as ideias de Saviani (2004), quando assinala que: 
[...] os cursos de preparação de professores devem visar à formação de seres humanos plenamente cultos, profundamente conhecedores da história concreta dos homens, em lugar da formação de indivíduos "curtos", preconizada pela atual política de formação de professores que vem incentivando os cursos de curta duração dos institutos superiores de educação e suas escolas normais superiores (SAVIANI, 2004, p. 48, grifo nosso).

Acreditamos, portanto, em um modelo de formação mais abrangente, que rompa com a visão dicotômica do modelo clássico, buscando uma nova perspectiva de formação continuada de professores (CANDAU, 1996). Nessa mesma perspectiva, Nóvoa (1995) afirma que a formação do professor deve estimular o desenvolvimento da visão crítica e reflexiva, que Ihe forneça os meios de aprimoramento do pensamento e das práticas autônomas e facilite a dinâmica do investimento na autoformação participativa, isto é, em formação construída não somente em processos solitários, mas com base na participação colegiada. É inerente, portanto, que as ações de FC conduzam os docentes a uma reflexão sobre sua prática e/ou sobre a de seus pares. A esse respeito, Carvalho e Alonso (1999) ressaltam que esse tipo de formação não possui caráter cumulativo, isto é, não se trata de um processo de acúmulo de conhecimentos, mas sim de um processo de "reflexão crítica sobre a própria experiência e em interação não só com os outros elementos da comunidade escolar, como também com os outros segmentos da sociedade" (CARVALHO; ALONSO, 1999, p. 51).

Desse modo, o processo formativo deve se constituir como espaço de interlocução em que formadores e professores em formação possam, por meio do diálogo, construir novos conhecimentos ou (re)significar os já existentes. Nesse processo, teoria e prática não são concebidas como instâncias isoladas ou contraditórias, mas constituem-se como uma unidade, haja vista que a tomada de consciência acerca do saber construído no exercício docente e as relações estabelecidas com os saberes teóricos devem ser entendidas como fontes de reflexão sobre a prática, afirmando, desse modo, o caráter indissociável de teoria e prática. 
Nesse sentido, reiteramos a nossa compreensão de FC como uma ação contínua, a qual "não pode reduzir-se a cursos de curta duração, ao contrário, é necessário que a interpretemos como uma trajetória permanente de aprendizagem, reforçada por situações de estudos e reflexões sobre as ações pedagógicas" (COSTA-HÜBES, 2008, p. 273). Assim, o processo de FC deve ser compreendido de forma dinâmica, por meio do qual, ao longo do tempo, um profissional vai adequando os conhecimentos relativos à sua formação inicial às necessidades da atividade profissional no contexto em que se encontra inserido.

A FC deve ser contextualizada na sua dimensão cultural, social e política, pois seria inútil se, ao "discutir o processo de formação continuada, desconsiderasse a escola como um espaço cultural, social e político, tratando o ensino da língua como transmissão de conhecimentos neutros e desvinculados do contexto particular de ação" (MAGALHÃES, 2004, apud COSTA-HÜBES, 2008 , p. 280). Corroborando tais pressupostos, Candau (1996, p. 149) pontua que a:

[...] formação contínua não pode ser concebida como um processo de acumulação (de cursos, palestras, seminários etc., de conhecimentos ou de técnicas), mas sim como um trabalho de reflexividade crítica sobre as práticas e de (re)construção permanente de uma identidade pessoal e profissional, em interação mútua.

Defendemos, portanto, um modelo alternativo de formação capaz de garantir a formação contínua do professor com "finalidades emancipatórias, críticas, reflexivas e transformadoras; e que se paute no aprofundamento teórico, aliando-o às reflexões da prática da sala de aula" (COSTA-HÜBES, 2008, p. 329). Essa é a concepção de formação que assumimos frente a ação executada na pesquisa. Ao aproximar a universidade da Educação Básica anos iniciais - defendemos a perspectiva que a atuação na FC de profissionais da educação deixa de ser uma tarefa eventual das universidades, executada a partir de demandas dos sistemas de ensino, e passa a ser entendida como um processo articulado à formação inicial e integrado à prática profissional dos docentes nas instituições de ensino. 
A partir dessa compreensão, que concebe o desenvolvimento profissional como um continuum, o professor formador deixa de desempenhar o papel de mero transmissor de conhecimentos e passa a ser mediador do processo de construção de conhecimentos, tornando-se responsável pela ponte entre os conhecimentos científicos (teóricos) e a ação pedagógica (prática).

Assim compreendidas as ações de $\mathrm{FC}$, na sequência retomamos alguns conceitos acerca da compreensão de leitura em diferentes contextos históricos e, por conseguinte, sua influência no ensino de Língua Portuguesa (doravante LP) no Brasil.

\section{Concepções de Leitura: Influências no Ensino}

Segundo Menegassi e Angelo (2005), o desenvolvimento dos estudos e das diferentes teorias que perpassam o ensino de leitura (influenciado pela concepção de língua e de linguagem) nas escolas brasileiras está atrelado ao desenvolvimento da própria Linguística3, como ciência que estuda a linguagem humana articulada, no caso, à fala e à escrita. Esse burilamento da linguagem alterou também o cenário no tocante ao ensino de LP, pois, se no princípio o foco era um ensino voltado às unidades isoladas da língua (letras, fonemas, palavras, frases, texto), hoje tornou-se objeto de ensino o texto como elemento representativo de determinado gênero discursivo.

A premência de revisitar as principais concepções de leitura (e suas influências) que permearam ou ainda permeiam o ensino de LP dá-se mediante à compreensão de que toda e qualquer metodologia de ensino relaciona-se a uma escolha política (social) que envolve teorias de compreensão e de interpretação da realidade. Assim, o entendimento que temos acerca da língua(gem) ou a concepção revelada na prática pedagógica do professor (por meio das atividades) apresentam-se como um fator significativo e condutor para o ensino de LP.

\footnotetext{
${ }^{3}$ Segundo os autores, as vertentes que surgiram a partir da linguística foram: a Psicolinguística, - Gerativismo, a Sociolinguística, a Pragmática, a Linguística Aplicada, a Análise do Discurso, a Linguística Textual, dentre outras.
} 
Quanto às diferentes compreensões de língua(gem) ao longo dos anos, Bakhtin e Volochinov (2004) as configura como: (1) Subjetivismo idealista; (2) Objetivismo abstrato e (3) Concepção dialógica de linguagem. No Brasil, encontramos em Geraldi (2004) as seguintes denominações correspondendo aos apontamentos de Bakhtin: (1) Linguagem como expressão do pensamento; (2) Linguagem como instrumento de comunicação e (3) linguagem como forma de interação. Tais concepções possuem uma relação direta com as práticas de leitura, uma vez que incorporam a essência, ou ainda, o que cada uma dessas concepções priorizam. Assim, coexistem diferentes perspectivas de leitura: (1) perspectiva do autor; (2) perspectiva do texto, perspectiva do leitor e, por fim, (3) a perspectiva autor-texto-leitor. Em relação a essas perspectivas, Menegassi e Ângelo (2005, p. 18) afirmam que:

Os pressupostos teóricos que amparam cada uma dessas diferentes perspectivas de leitura envolvem uma visão diferente do que consiste 0 ato de ler e orientam e/ou justificam determinadas propostas didáticas em torno da compreensão da leitura, e da formação e do desenvolvimento do leitor na escola brasileira.

Com o objetivo de debatermos as concepções de leitura e suas influências no e para o ensino, fazemos na sequência, uma breve retomada, destacando suas características e sua (não) presença na prática pedagógica.

A perspectiva de leitura com foco no autor, compreende o indivíduo "dono" de seu dizer e de suas ações. O texto, neste contexto, aparece como um produto lógico do autor, algo pronto e acabado, cabendo ao leitor o papel passivo de extrair do texto essas representações mentais. Para Koch e Elias (2010), nesse nível, "a leitura é, assim, entendida como a atividade de captação das ideias do autor, sem se levar em conta as experiências e os conhecimentos do leitor" (KOCH; ELIAS, 2010, p. 10). Portanto, o sentido está restrito ao autor e, por isso, o entorno do texto não é considerado.

Em uma outra maneira de conceber a linguagem, a leitura aparece com foco no texto, ao qual o sujeito torna-se "assujeitado" (KOCH; ELIAS, 2010, p. 10), pois o ato de ler restringe-se ao texto, ficando a cargo do leitor a 
identificação de sua organização interna. O sentido, portanto, está no texto, cabendo ao leitor decodificá-lo.

O texto, por conseguinte, nessa perspectiva, é estudado sem nenhuma ligação com o contexto de produção e de recepção, sendo compreendido como "produto da codificação de um emissor a ser decodificado pelo leitor/ouvinte, bastando a este, para tanto, o conhecimento do código utilizado" ( $\mathrm{KOCH}$; ELIAS, 2010, p. 10). Consequentemente, o sentido repousa sob o texto, naquilo que está codificado e materializado nele. Ao leitor, portanto, caberia se relacionar com esse conjunto de signos, reconhecendo-os e reproduzindo-os.

Subjacente à perspectiva do texto, o leitor volta-se para ele a fim de extrair ou obter uma(s) informação(ões). Dessa forma, constitui-se um modelo de leitura denominado ascendente (bottom-up), isto é, "um processamento que vai do texto para o leitor, como se ascendesse, considerando-se a posição do texto que normalmente está abaixo dos olhos" (MENEGASSI; ANGELO, 2005, p. 19). É como se os olhos fossem o "meio" para o leitor extrair o conteúdo do texto. Vislumbramos, nesse modelo de leitura, um processo linear, no qual os leitores terão acesso às mesmas informações (a partir da leitura do texto), considerando que esses compartilham de algo comum, isto é, de um conjunto de signos. Tal postura é evidenciada por Leffa, o qual pontua que "na medida em que ler é extrair significados, um mesmo texto produz sempre os mesmos significados, pelo menos em leitores de um mesmo nível de competência" (LEFFA, 1999, p. 6). Esse movimento uniforme e linear da leitura prevê a homogeneidade, pois, se todos leem as mesmas coisas, pretende-se que todas saibam as mesmas coisas da mesma forma. O professor, nesse espaço, transmite as informações sobre o texto pela sua ótica, a qual é determinante na atribuição de sentido.

O foco da leitura está no ato de decodificar, uma vez que a postura do leitor é inativa diante do produto (texto). Tudo é dito e encontrado no texto, ou conforme Koch e Elias (2010, p. 10) "tudo está dito no dito". Complementa essa assertiva Leffa $(1999$, p. 18) dizendo que: 
Tudo está no texto, mas separado em duas camadas: uma camada profunda, que é o conteúdo a ser acessado pelo leitor, e uma camada superficial, que recobre o conteúdo, mostrando-o com maior ou menor clareza, dependendo justamente de sua transparência. Como na imagem de Thoreau, o texto é o vidro que protege a paisagem numa pintura. Ler é extrair esse conteúdo, e a leitura será tanto melhor quanto mais conteúdo extrair.

O texto, além de ser tomado como produto, também se torna pretexto para a proposição de variadas atividades gramaticais, com base em fragmentos retirados do mesmo e sem a devida importância ao seu contexto de uso. Dessa forma, a compreensão que se tem é que o significado reside na palavra em seu estado inerte (dicionário) e não no uso que ela assume dentro de um (con)texto. Assim, Kleiman (1996) pontua que esse tipo de trabalho prioriza "uma série de automatismos de identificação (decodificação) e pareamento das palavras do texto com palavras idênticas numa pergunta ou comentário" (KLEIMAN, 1996, p. 20). Nessa mesma direção, Costa-Hübes (2009, p. 133) assegura que esse "modelo" de ensino busca nos exercícios de siga o modelo a possibilidade de o aluno "decorar estruturas bem construídas e transpô-las para a produção de textos escritos" (grifos da autora).

Imbuídos pelos princípios inatista da língua(gem), passamos da compreensão de leitura anterior - foco no texto - para a perspectiva com foco no leitor, compreendido agora como aquele que possui uma carga genética e informações armazenadas no interior da sua mente as quais possibilitam a atribuição de sentido ao que se lê. Surge, portanto, a abordagem de leitura descendente (top-down). Segundo Smith (1989 apud CASTELA, 2009, p. 2627):

\begin{abstract}
Nessa perspectiva, enfatiza-se o processamento top-down ou descendente da informação, em que a leitura constitui um processo de atribuição de significados no qual o leitor utiliza um processo não linear, formula hipóteses e inferência ${ }^{4}$ de informações extralinguísticas, transporta seus conhecimentos e experiências prévias para o material lido e ativa seus esquemas mentais.
\end{abstract}

\footnotetext{
4"as inferências na compreensão de texto são processos cognitivos nos quais os falantes ou ouvintes, partindo da informação textual e considerando o respectivo contexto, constroem uma nova representação semântica" (MARCUSCHI, 2008, p. 249).
} 
Como podemos vislumbrar, o autor volta a atenção para o que chamam de esquemas mentais. Para ele, essa expressão diz respeito às estruturas cognitivas do leitor, as quais possibilitam armazenar as informações sobre determinado assunto, aproximando-o, pelas semelhanças, ou distanciando-o, pelas suas diferenças. Dessa forma, "a obtenção de sentido não se dá através de um processamento linear, palavra por palavra, mas se dá sempre por força da contribuição do leitor, dos conhecimentos armazenados na sua memória, isto é, dos conhecimentos prévios" (MENEGASSI; ANGELO, 2005, p. 18). Kato (1995) nomeia o leitor (nessa abordagem) de construtor, pois "possui maior capacidade para ler nas entrelinhas, acessar as informações implícitas e realizar predições, recriando o texto" (CASTELA, 2009, p. 27).

O processamento de leitura, nesse caso, coloca o leitor numa posição ativa, em que ele terá que mobilizar suas habilidades e competências cognitivas para construir uma compreensão ao texto. Ademais, essa abordagem privilegia o processo em detrimento do produto fato esse que possibilita um mesmo texto ter muitos significados, uma vez que o produto é o mesmo, mas o processo é diferente, haja vista as vivências e experiências variadas dos leitores. Essa relação também é estabelecida por Menegassi e Ângelo (2005), os quais corroboram a ideia de que "pessoas diferentes lendo o mesmo texto apresentam variações no que se refere à compreensão do mesmo, pois variam os seus propósitos, seus conhecimentos prévios [...] suas atitudes, seus esquemas conceptuais, a cultura de cada uma" (MENEGASSI; ANGELO, 2005, p. 23). Assim, na perspectiva cognitivista,

[...] a leitura não envolve apenas o input visual, mas também informações não visuais, do universo cognitivo do leitor. É esta interação das pistas visuais com o conhecimento armazenado na memória do leitor que lhe possibilita antever, ou predizer, o que ele irá encontrar no texto (KATO, 1995, p. 64).

Perpassando por tais pressupostos, os quais revelam a perspectiva de leitura descendente, ratificamos o perfil soberano do leitor sobrepondo-se ao texto, uma vez que o significado dá-se, não pela relação texto/leitor, mas sim 
pelas informações mnemônicas armazenadas pelo leitor ao longo dos anos e ativadas no momento da leitura. Nesse sentido, o mesmo decodifica rapidamente o que está escrito, se prendendo em ideias primárias, utilizando-se de um alto grau de inferenciações com caráter de adivinhações, o que conduz a uma leitura apressada e, muitas vezes, equivocada.

Já a concepção de linguagem como meio de interação tem a perspectiva de leitura com foco na interação-texto-leitor, pois concebe a língua não como simplesmente um conjunto de regras, mas como um sistema dinâmico, dialógico e social. Conforme Koch e Elias (2010), "os sujeitos são vistos com autores/construtores sociais, sujeitos ativos que - dialogicamente - se constroem e são construídos no texto, considerando o próprio lugar da interação e da constituição dos interlocutores" (KOCH; ELIAS, 2010, p. 10-11, grifos das autoras).

A leitura, de acordo com essa perspectiva, vai-se delineando numa cadeia de sentidos e significados advindos da interação do leitor com o texto. Não se trata apenas de extrair significado do texto, ou ainda, num processo de retomada, buscar o conhecimento armazenado na memória do leitor; trata-se de uma leitura crítica, pois, "ao perceber a incompletude do que está exposto no papel, o sujeito age ativamente, trazendo para o texto seus conhecimentos e utilizando a palavra do outro para formular sua própria, produzindo um elo entre o que já foi dito e o novo" (MENEGASSI; FUZA; OHUSCHI, 2011, p. 495). Logo, a compreensão se dá mediante a consideração do contexto sóciohistórico (de produção e de leitura) associado à atividade dialógica, mantida entre leitor, texto e autor.

Nessa perspectiva, o sentido não se restringe ao texto, nem ao autor. 0 sentido é construído na interação texto-sujeitos, sendo, dessa forma, considerados, além dos aspectos da textualidade, os aspectos discursivos do texto. Nesse sentido, as experiências do leitor e seus conhecimentos são considerados a fim de auxiliar na construção de sentidos. A leitura, portanto, é contemplada pela produção de sentido. Koch e Elias (2010, p. 11) afirmam que: 
A leitura é, pois, uma atividade interativa altamente complexa de produção de sentidos, que se realiza evidentemente com base nos elementos linguísticos presentes na superfície textual e na sua forma de organização, mas requer a mobilização de um vasto conjunto de saberes no interior do evento comunicativo (grifos da autora).

Essas concepções de linguagem e de leitura são reforçadas pelos documentos oficiais e em avaliações nacionais, as quais focalizam, de forma intensa, o domínio de diferentes gêneros discursivos, bem como o uso efetivo da língua em diversas situações sociointerativas. Dessa forma, assumimos, nos encontros de FC, a linguagem numa perspectiva dialógica, uma vez que nossas ações ocorrem por meio da interação entre sujeitos, e, ainda, acreditamos que:

[...] o modo como ensinamos, as nossas ações na sala de aula são afetadas ideologicamente, pois a forma como concebemos o ensino de língua e a alfabetização, as escolhas que fazemos em relação a materiais e a métodos podem contribuir para a formação de homens críticos, ou de homens alienados, tendo em vista que as mesmas estão inevitavelmente apoiadas em concepções de homem, de sociedade, de linguagem, as quais incorporamos ao longo de nossa constituição sócio-histórica. Para interagir plenamente no mundo letrado é preciso mais que um domínio do código. Requer que a linguagem seja tratada na sua perspectiva discursivo-enunciativa, em práticas sociais de leitura, de escrita e de fala (BAUMGÄRTNER; COSTA-HÜBES, 2007, p. 13).

Anuindo com tais pressupostos, compreendemos a necessidade de um (re)direcionamento do trabalho pedagógico, que considere a linguagem como o ponto de partida da prática docente, uma vez que, por meio da linguagem, somos inseridos no meio social e possibilitados a interagir nas mais diversas situações cotidianas. Assim, a ação docente deve, também, ter clareza de quais os princípios teóricos (revelados nas atividades pedagógicas) guiam a sua prática, pois são eles que definirão e conduzirão o processo de ensino e aprendizagem. Partindo desses pressupostos, é que lançamos, na sequência, um olhar analítico-interpretativo aos dados coletados nessa pesquisa por meio de entrevista semiestruturada.

\section{O Que Dizem os Professores? Revelações e Confirmações}


A entrevista semiestruturada com grupo focal, contou com a participação da totalidade (4) dos professores que, durante as ações de FC, atuavam com turmas de $5^{\circ}$ ano no município. O critério que moveu nossa escolha deveu-se ao fato de julgarmos, a princípio, a proximidade maior desses docentes com o instrumento avaliativo "Prova Brasil" e, por conseguinte, mesmo que indiretamente, com a concepção de leitura subjacente a essa avaliação, pois tínhamos o objetivo de buscar indícios ou afirmações em relação às concepções de leitura reveladas na/pela fala dos docentes investigados.

Devido ao espaço dedicado para esse trabalho, nos deteremos na análise apenas a duas questões abordadas durante a geração de dados, quais sejam, (1) O que é leitura para você? e (2) O que é ser um (bom) leitor?

Em resposta à primeira questão escolhida para o estudo da compreensão sobre leitura, os docentes teceram os seguintes comentários:

P1 - Então a leitura pode ser tanto através da escrita como visual. Então ela vai bem além (ela quer a formação de um aluno crítico capaz de se relacionar) com a sociedade, de interpretar diferentes textos da sociedade em que ele vive na interação conjunta social.

P2 - Leitura é tudo né... seria uma leitura do mundo da vida assim estar informado ... com a situação com o local né.. ler é tudo ... sem leitura você não consegue você não tem conhecimento... a leitura possibilita instruir passar instrução diverte também né informa...depende depende a situação né.. mas eu vejo assim a função principal é a instrução ela instrui né... através dela a gente pode buscar informações.

P3 - Leitura é a gente estar sempre buscando conhecimento pra ta passando para o aluno assim ... Assim né o conhecimento de / ampliando o conhecimento de mundo. a leitura possibilita ampliar os meus conhecimentos de mundo e pra passar também pro meu aluno ne através da leitura.

P4 - Pra mim leitura é tudo é o aluno precisa de leitura ler e interpretar porque só ler ... só decodificar ali não saber o que. Esta lendo não é ler então pra mim leitura é isso. É tudo na vida da pessoa saber ler e saber o que esta lendo.

Diante das respostas, interpretamos que P1 apresenta um conceito de leitura com indícios que se aproximam da concepção interativa de leitura. Para o docente, a leitura é um ato de exercício da cidadania, pois, por meio dela, 
tem-se a possibilidade de compreender o mundo. Entende que é por meio da leitura que podemos formar cidadãos críticos, uma condição indispensável ao exercício da cidadania, na medida em que o sujeito tem a possibilidade de compreender as inúmeras vozes que se manifestam no contexto social e agir mediados por esse entendimento, ou seja, para um exercício ativo da cidadania, é necessário reconhecer o seu papel na sociedade e inserir-se criticamente na realidade.

Outro aspecto revelado por $\mathrm{P} 1$ e que merece nosso destaque é a expansão do conceito de leitura revelada na fala: "Então a leitura pode ser tanto através da escrita como visual". Nesse excerto, vemos que há uma compreensão ampliada que aponta para a leitura não apenas como mero mecanismo de desvelamento dos sinais gráficos presentes no texto (leitura com foco no texto). Ao considerar os signos não verbais, o professor evidencia que a formação de sujeitos leitores implica na capacidade de conviver e compreender as diferentes linguagens e, nesse caso, na capacidade de utilizar textos verbais e não verbais como instrumentos indispensáveis à sua participação efetiva na realidade social. Para tanto, a compreensão de que as práticas de leitura não se restringem a materiais escritos - texto verbal - é fundamental numa sociedade em que a presença e 0 apelo pelos recursos visuais estão constantemente presentes. Portanto, o domínio dos diferentes tipos de linguagens e de seus recursos significativos é imprescindível no momento da interação nos mais diversos campos da atividade humana.

Ainda em relação à concepção de leitura do $\mathrm{P} 1$, evidenciamos o comentário: "Então ela vai bem além ela quer a formação de um aluno crítico capaz de se (relacionar) com a sociedade, de interpretar diferentes textos da sociedade em que ele vive na interação conjunta social". Tais palavras indicam uma tentativa do informante em se aproximar da concepção interacional de leitura (KOCH; ELIAS, 2010), por meio da qual o sujeito/leitor, ao interagir com o autor e o texto, amplia seu conhecimento de mundo e, consequentemente, sua inserção social. Essas evidências podem ser demarcadas pelas expressões "um aluno crítico capaz de se (relacionar) com a sociedade", e ainda, 
"interpretar diferentes textos da sociedade em que ele vive na interação conjunta social", as quais levantam dois pontos fundamentais da leitura com foco no autor-texto-leitor: (a) interação entre sujeitos e (b) interação com textos que circulam socialmente. As afirmações nos conduzem à compreensão de que, para $\mathrm{P} 1$, a leitura, além de ser uma atividade interativa entre os diferentes sujeitos/elementos do discurso - autor-texto-leitor -, é concebida como uma prática social. $\mathrm{O}$ entendimento que ora $\mathrm{P} 1$ deixa transparecer dialoga com o que Kleiman (1996) advoga: "quanto à concepção de leitura [...] consideramos esta uma prática social que remete a outros textos e outras leituras" (KLEIMAN, 1996, p. 10). Da mesma forma, pontuam Koch e Elias (2010), Menegassi e Ângelo (2005), Rojo (2002), Fuza (2010), dentre outros.

Em relação a esse mesmo questionamento, P2 deixou transparecer, em seu discurso, expressões com uma perspectiva de leitura com foco no texto.

Muitos são os autores que tratam a ideia da leitura como "leitura de mundo", como a ecoada na voz do docente P2. Podemos destacar Freire (2004), o qual assinala que a leitura de mundo precede a leitura da palavra. Assim, "toda leitura da palavra pressupõe uma leitura anterior do mundo, e toda leitura da palavra implica a volta sobre a leitura no mundo, de tal maneira que ler mundo e ler palavra se constituíam um movimento em que não há ruptura, em que você vai e volta" (FREIRE, 2004, p. 15). De fato, se analisarmos essa citação do ponto de vista da leitura como prática social, veremos que muito antes de a criança adentrar na escola e começar a codificar e decodificar sinais já está imersa numa sociedade que vive e interage cotidianamente com a cultura da leitura e da escrita.

Contudo, ao lado dessa compreensão, P2 revela em sua fala um posicionamento neoliberal, ou seja, a leitura tomada pelo caráter utilitário. Essa tendência é evidenciada quando o docente diz "sem a leitura você não consegue ... você não tem conhecimento", e ainda "mas eu vejo assim a função principal é a instrução ela instrui né.. através dela a gente pode extrair informações...". Concordamos com a docente quando assinala os diferentes 
objetivos de leitura "instruir", "divertir" e "informar". De fato, considerando a vertente interacionista de leitura, podemos afirmar que:

[...] os usos da leitura, nessa perspectiva, estão ligados à situação; são determinados pelas histórias dos participantes, pelas características da instituição em que se encontram, pelo grau de formalidade ou informalidade da situação, pelo objetivo da atividade de leitura, [...]. Tudo isso realça a diferença e a multiplicidade dos discursos que envolvem e constituem os sujeitos e que determinam esses diferentes modos de ler (KLEIMAN, 1996, p. 14, grifos nossos).

No entanto, apesar de P2 reconhecer que ao ler temos diferentes intencionalidades, vislumbramos fortes ecos do conceito estruturalista de leitura, uma vez que afirma que "através dela a gente pode extrair informações". Essa noção de leitura a concebe como processo de extração do significado do texto (LEFFA, 1996, MENEGASSI; ANGELO, 2005). Nesse sentido, o leitor vai ao texto para capturar informações presentes em sua linearidade, utilizando-se da estratégia de decodificação. Trata-se, conforme já pontuamos, de um processo ascendente de leitura (bottom-up), ou seja, parte-se do texto para o leitor, num movimento de relação unilateral. Linguagem, para P2, portanto, funciona como um veículo de informação, de modo que, em termos de leitura, o leitor assume o papel de sujeito passivo diante da situação, uma vez que Ihe é solicitado apenas captar a mensagem proferida pelo emissor. Esse entendimento é explicado por Bakhtin (2003, p. 289-290):

[...] a linguagem é considerada do ponto de vista do locutor como se este estivesse sozinho, sem uma forçosa relação com os outros parceiros da comunicação verbal. E, quando o papel do outro é levado em consideração, é como um destinatário passivo que se limita a compreender o locutor. $\mathrm{O}$ enunciado satisfaz ao seu próprio objeto (ou seja, ao conteúdo do pensamento enunciado) e ao próprio enunciador. A língua só requer o locutor - apenas o locutor - e o objeto de seu discurso, e se, com isso, ela também pode servir de meio de comunicação, esta é apenas uma função acessória, que não toca à sua essência.

A visão da leitura como veículo de informação também é compartilhada pelo terceiro entrevistado, P3, que relaciona a leitura à possibilidade de "ampliar os [...] conhecimentos de mundo e [...] pra passar também pro meu 
alund". Certamente, como já apregoado, a leitura possibilita a busca de informações e, consequentemente, amplia o nosso conhecimento de mundo. Contudo, vemos que a preocupação do docente é acumular saberes específicos para transmiti-los aos alunos. Logo, estamos diante de um evento monológico, no qual a linguagem, conforme criticado por Geraldi $(1993,2004)$ e Travaglia (2001), serve apenas para transmitir informações de um emissor a um receptor.

Avançando nessa análise, temos a resposta de P4 que acena para uma compreensão de leitura além da decodificação. Apesar de uma justificativa frágil, P4 considera que ao ler, o aluno precisa interpretar aquilo que lê. Essa compreensão indica vestígios da concepção interacionista de leitura, pois se preocupa com uma prática que garanta a formação de leitores ativos e participativos na construção de sentido(s) do texto.

A partir do exposto pelos docentes sobre como compreendem a leitura, chegamos a um ponto da análise em que se torna evidente a importância de conhecermos o que, na opinião dos professores, é um leitor, em função das concepções de leitura apresentadas pelos próprios participantes. Portanto, a segunda indagação foi no sentido de averiguar o conceito de leitor apregoado por cada um dos participantes dessa entrevista. Da interpelação - O que é ser leitor? - durante o diálogo surgiram outras: em sua opinião, o que o aluno precisa saber para ser um bom leitor? Que conteúdos ele precisa dominar? Na ocasião, tivemos as seguintes respostas:

$\mathrm{P} 1$ - ser leitor eu acho que é a pessoa se doar ... especialmente aí pra o uso dos livros né... dos diferentes gêneros e gostar. Porque para o aluno ser um bom leitor /.../ o aluno ser capaz de identificar os diferentes gêneros de textos é ... para que ele seja um bom leitor ele precisa saber identificar que tipo de texto ele está fazendo a leitura né

P2 - ...Ser leitor é... ser aquilo que/ler ... buscar informações é até não precisa saber assim as letras né os códigos formais .. mas o leitor é aquele que busca informação que lê para se informar.. Saber entender ne aquilo que está lendo ... decodificar as palavras.

P3 - Na escola eu vejo dessa maneira... e quanto aos conteúdos escolares eu vejo que a leitura de todos os gêneros textuais 
facilita para a formação de um bom leitor.. ler todos os tipos de gêneros textuais... livros....revistas tudo que tiver ao seu alcance... o bom leitor é aquele que domina os diferentes gêneros textuais (grifos nossos).

P4 - um bom leitor ele precisa dominar o conteúdo do que ele leu saber contar o conteúdo /.../ a escrita ... dominar os gêneros textuais ... /.../agora estou trabalhando o gênero bilhete eles já estão escrevendo bilhete... porque ele tem que buscar através do gênero tem que ler e reler né eu faço assim que eles escrevem e leiam para mim ou as vezes trocam entre eles...

Pelas respostas advindas das interpelações podemos sustentá-las a partir de um olhar analítico em duas direções quanto ao que consideram por (bom) leitor: 1) como aqueles que dominam os diferentes gêneros discursivos; e 2) como aqueles que vão ao texto para buscar informação. Sustentadas no primeiro enfoque, encontramos as respostas de P1, P3 e P4 que, além de outros comentários, expõem que o aluno, para ser um (bom) leitor, necessita ter o acesso e o domínio dos diferentes gêneros discursivos.

No discurso de P1, por exemplo, é perceptível a preocupação quanto ao papel da escola na formação de leitores, o que pode ser evidenciado no início da sua fala: "Isso que é o problema transformar / conseguir fazer do aluno um leitor né. Esse é o desafio... é um papel que nós professores temos a.: fazer ai ainda né... temos muito a ser trabalhado ainda nas escolas". Apesar de considerarmos que a leitura é um processo que não se limita ao âmbito escolar, reforçamos que a escola deve, sim, se preocupar com o trabalho sistemático de leitura, o qual possa conduzir os educandos a uma formação que favoreça a interação social entre sujeitos historicamente situados. Corroboramos a afirmativa de P1 quando sinaliza que a escola (professores) tem muito ainda a contribuir com a formação de sujeitos leitores. De fato, o que observamos é que, muitas vezes, a leitura é guiada por influência dos modelos tradicionais e por concepções superficiais e frágeis que determinam o ato de ler. Solé (1998), em seus estudos, discorre acerca dessa problemática e esclarece que

O problema do ensino de leitura na escola não se situa no nível do método, mas na própria conceituação do que é leitura, da forma em que é avaliada pelas equipes de professores, do papel que ocupa nos 
Projeto Curricular da escola, dos meios que se arbitram pra fortalecêla, naturalmente, das propostas metodológicas que se adotam para ensiná-la (SOLÉ, 1998, p. 33).

O posicionamento da autora esclarece e ratifica a primeira interpelação lançada aos professores "O que é leitura para você?". Nesse sentido, reconhecer como o professor concebe a língua(gem) e, nesse caso, a leitura é um ponto fundamental no ensino de língua materna, haja vista que mediante sua concepção é que o trabalho em sala de aula se estruturará. Nessa direção, somos provocados por Geraldi (1997), a refletir sobre o trabalho com a leitura numa perspectiva dialógica em sala de aula. $O$ autor sinaliza que a primeira questão levantada para uma aula de leitura deve ser: para que se lê o que se lê? Em relação a esse questionamento, o próprio autor assinala a incoerência presente nas metodologias adotadas para o ensino, uma vez que "Os alunos, leitores e, portanto interlocutores, lêem para atender a legitimação social da leitura externamente constituída fora do processo em que estão, eles, leitores/alunos, engajados" (GERALDI, 1997, p. 169).

$\mathrm{Na}$ fala de $\mathrm{P} 1$, observamos essa preocupação quanto ao o que é ler. $\mathrm{Em}$ dois momentos o docente evidencia a importância da leitura de diferentes gêneros discursivos: a) ser leitor eu acho que é a pessoa se doar ... especialmente ai pra o uso dos livros né... dos diferentes gêneros textuais; e b) Porque para o aluno ser um bom leitor /.../ o aluno ser capaz de identificar os diferentes gêneros de textos é ... para que ele seja um bom leitor ele precisa saber i-dentificar que tipo de texto ele esta fazendo a leitura/.../. Percebe-se, na resposta de $\mathrm{P} 1$, que o conceito de leitor se aproxima da concepção interacionista. Apesar de ele não fazer relação aos termos característicos dessa perspectiva, como por exemplo "interação", "contexto social" e "prática social", o docente sinaliza para o instrumento de ensino dessa concepção: os gêneros discursivos. Sustentado pela perspectiva bakhtiniana de gênero discursivo, destaca Faraco (2003) que um trabalho de leitura deve partir da vinculação dessas práticas sociais ao contexto sócio-histórico-ideológico, por meio da relação dialógica que cada produção de linguagem (enunciado) estabelece com 
outros enunciados. Tal processo é fundamental para orientar as práticas de leitura de gêneros discursivos, haja vista que é a percepção de suas relações dialógicas com outros enunciados que possibilitará ao leitor uma efetiva interlocução com o texto.

P1 sinaliza também a relevância do trabalho com os diferentes gêneros discursivos. Endossamos esse comentário pontuando que, quanto mais conhecimento textual o leitor tiver e quanto maior a sua exposição à variedade de práticas sociais, maior será sua capacidade compreensiva, haja vista que o conhecimento de diferentes tipos de discurso determinará, em grande medida, sua performance interativa (KLEIMAN, 2000).

Ainda acerca do depoimento de P1, observamos que o docente chama a atenção para a necessidade de o (bom) leitor:

/.../dominar os aspectos gramaticais muitas vezes ocorre dentro da sala de aula é a questão de pontuação/domínio da pontuação porque pra compreender uma história que esta lendo ele tem que dominar a pontuação porque se ele faz uma leitura mal feita também não vai consegui aquilo que ele esta lendo né [...].

Compartilhamos desse posicionamento no sentido de que a pontuação tanto na escrita quanto na leitura apresenta, como afirma Schneuwly (1998), um duplo caráter: correlacionada à função de segmentar o texto, a pontuação tem por finalidade organizá-lo. Ademais, o autor enfatiza que os sinais de pontuação não mais marcam pausas para respirar durante a leitura em voz alta, conforme apregoada pela gramática tradicional, ao contrário, constituem, marcas de organização textual, traços de operações de conexão e, sobretudo, de segmentação do texto escrito (SCHNEUWLY, 1998).

Ao afirmar que o aluno precisa dominar a pontuação para que a compreensão se efetive, o docente deixa transparecer, mesmo que implicitamente, que tais sinais, em especial na leitura, se configuram como recursos da textualidade e, por conseguinte, contribuem para os efeitos de sentido construídos pelo leitor em interação com o texto. Respeitar, portanto, a 
pontuação, fazer as entonações adequadas, são aspectos primordiais, para que se compreenda o que alguém lê, quando se trata de leitura oralizada.

Compreendendo que a pontuação, nessa perspectiva, não obedece rigorosamente à fixidez imposta pela gramática normativa, outro aspecto relevante a esse estudo é o fato da estrita relação desse recurso gráfico com os gêneros discursivos. Considerando a proposição de Bakhtin (2003) acerca do conteúdo temático, construção composicional e estilo, atrelada à instabilidade dessas práticas sociais, observamos que a pontuação também é flexível à medida que tenta atender às especificidades dos diferentes gêneros discursivos. Pontuar é, pois, um recurso sintático e estilístico que, concatenado com as intenções do falante/leitor é utilizado a serviço da comunicação verbal.

Compartilha dessa necessidade o terceiro entrevistado. Em sua fala é possível identificar pontos comuns a P1 quando expõe que para ser bom leitor o aluno precisa dominar os diferentes gêneros discursivos. Tal fato é evidenciado no seguinte excerto:

P3 - /.../ eu vejo que a leitura de todos os gêneros textuais facilita para a formação de um bom leitor.. ler todos os tipos de gêneros textuais... livros... revistas tudo que tiver ao seu alcance... o bom leitor é aquele que domina os diferentes gêneros textuais.

Concordamos com P3 quando faz tal assinalamento, pois, numa perspectiva interacional-dialógica, um (bom) leitor é aquele que possui determinadas habilidades de leitura e conhecimento das principais características constitutivas do gênero. Nesse sentido, a partir de seu domínio, os alunos-interlocutores-leitores terão maiores possibilidades de interagir, de forma efetiva, com as práticas sociais que thes são apresentadas a cada dia, a cada convívio social, a cada situação comunicativa. Um leitor proficiente, nessa perspectiva de leitura, é, pois, aquele que consegue estabelecer um diálogo com o texto. Não se trata, portanto, de uma atividade simples, mas sim de um processo complexo, no qual se faz necessária a articulação de conhecimentos de ordens variadas - abordagem (sócio)cognitiva de leitura - aos conhecimentos específicos do gênero discursivo alvo da leitura. Partilha, 
também, desse ponto de vista, P4, o qual afirma que para o aluno ser "um bom leitor ele precisa dominar o conteúdo do que ele leu /.../ dominar os gêneros textuais ... /.../". Por esse excerto, percebemos que o docente não limita $o$ ato de ler ao processo de decodificação, pois adverte que o leitor precisa compreender o que ele leu. De fato, a leitura como decodificação "é uma prática muito empobrecedora [...] essa concepção dá lugar às leituras dispensáveis uma vez que em nada modificam a visão de mundo do aluno" (KLEIMAN, 2000, p. 23). Ler não é transformar sinais gráficos em sons, pelo contrário, ler é construir sentidos. Portanto no depoimento de P4 percebemos a relevância dada aos gêneros discursivos denotando uma concepção de leitura voltada à funcionalidade da linguagem.

Contudo, essa compreensão de leitura como produção de sentido não se materializa no discurso tecido por P2, o qual denuncia um entendimento de base estruturalista, veiculado ao caráter utilitário do ato de ler. Para P2, um (bom) leitor é "aquele que busca informação que lê para se informar...". Concordamos que tantos são os tipos de leituras com as quais nos deparamos no nosso dia a dia quantos são os objetivos relacionados a essas práticas sociais. Buscar informação é, pois, uma das finalidades da leitura, mas não se restringe a essa apenas.

Geraldi (1997) assinala que há quatro tipos de relações entre texto e leitura ${ }^{5}$, mas que essas não esgotam as muitas possibilidades, e sim devem inspirar outras práticas de leitura na escola. A busca de informação, por exemplo, quando não se limita ao ato de extrair da linearidade textual fragmentos e dados pontuais, pode ser de grande valia para o aluno, à medida que essas interpretações demandam a busca de outras informações, de outros modos com que os outros viram e veem experiências semelhantes. Dada essa compreensão, o autor nos diz que "a leitura incide sobre 'o que se tem a dizer' porque, lendo a palavra do outro, posso descobrir nela outras formas de pensar que, contrapostas às minhas, poderão me levar à construção de novas formas"

${ }^{5}$ (1) A leitura-busca-de-informações; (2) A leitura-estudo-do-texto; (3) A leitura-pretexto; (4) A leitura-fruição-do-texto. 
(GERALDI, 1997, p. 171). Não se trata, portanto, apenas do movimento de extração de informações, conforme indicado por P2.

Ademais, no depoimento de $\mathrm{P} 2$, ainda verificamos resquícios da vertente estruturalista de leitura quando diz que o leitor deve "entender /.../ aquilo que está lendo... decodificar as palavras". Apesar de afirmar que ele primeiro necessita entender 0 que está lendo, sua fala final repousa sobre 0 ato mecânico de decodificar. A despeito de o processo de codificação ser uma estratégia que possibilita o leitor desvelar o mundo da escrita, defendemos que "[...] o essencial na tarefa de decodificação não consiste em reconhecer a forma utilizada, mas compreendê-la num contexto concreto preciso, compreender sua significação numa enunciação particular" (BAKHTIN; VOLOCHINOV, 2004, p. 85).

\section{Conclusão}

O objetivo desse artigo foi apresentar alguns resultados gerados por meio da pesquisa (Stricto Sensu) A concepção de leitura na formação continuada: implicações no processo de organização da prática pedagógica. Propusemo-nos, mais especificamente, a analisar os dados gerados por meio da entrevista semiestruturada, focalizamos o olhar nas concepções de leitura reveladas no discurso dos docentes de $5^{\circ}$ ano do Ensino Fundamental I, inseridos no contexto de formação continuada oferecido pelo projeto Formação continuada para professores da educação básica nos anos iniciais: ações voltadas para a alfabetização em municípios com baixo IDEB da região Oeste do Paraná.

Observamos, por meio dessa pesquisa assim como de muitas outras, que, a despeito das preocupações e investimentos dos órgãos governamentais quanto às políticas públicas de formação dos professores nos últimos anos, ainda restam muitos desafios, principalmente no sentido de superar a fragmentação e o utilitarismo incutidos nesse processo, movendo-se em direção 
a uma concepção de FC como um espaço de reflexão permanente, ou ainda, conforme Nóvoa (1995), sob o eixo investigação-reflexão.

Mesmo que o projeto por nós ofertado ao município tentasse romper com esse paradigma (fragmentação, descontinuidade), confirmou-se, nos resultados advindos principalmente da entrevista, que as quarenta horas de FC oferecidas não foram suficientes para que o ensino da leitura ultrapassasse a concepção estruturalista e determinista, de tal forma que refletisse nas ações pedagógicas. É preciso ir além, estendendo-se as discussões e o tempo suficiente para que o conhecimento se consolide e se revele na prática. As dificuldades encontradas pelos docentes no redimensionamento da sua prática pedagógica dizem respeito às experiências e vivências de formações interpessoais estabelecidas face à realidade sócio-histórica, e o seu trabalho em torno da leitura repousa em práticas experenciadas historicamente, "determinadas não apenas por uma inconsistência teórica, mas também pela atuação de forças externas, de imagens interiorizadas" (MENEGASSI; ANGELO, 2005, p. 134). Dessa maneira, consoante aos fundamentos teóricos, "assumimos a necessidade de o professor se ver como um ser inacabado, incompleto que necessita de uma 'realimentação', já que sua formação continua ao longo de sua vida profissional" (MENEGASSI; ANGELO , 2005, p. 135).

Apesar de encontrarmos nos discursos dos docentes, indícios e tentativas de trabalho com a leitura com foco na interação autor-texto-leitor, o que pudemos vislumbrar também são defesas de práticas conservadoras e estruturalistas, que se sustentam sob o pressuposto de que 0 ato de ler se restringe ao processo de decodificação da língua escrita. Entretanto, acreditamos que por meio de uma política de formação efetiva possamos, mesmo que lentamente, inserir o docente em um contexto que possa além de se apropriar dos saberes científicos, mobilizar os conhecimentos cotidianos pessoais e profissionais a fim de atender aos propósitos educativos.

\section{Referências}


BAKHTIN, M. Estética da criação verbal. 3. ed. São Paulo: Martins Fontes, 2003.

BAKHTIN, M.; VOLOCHINOV, V. N. Marxismo e filosofia da linguagem. 11. ed. São Paulo: Hucitec, 2004.

BAUMGÄRTNER, C. T.; COSTA-HÜBES, T. C. Sequência Didática: uma proposta para o ensino da língua portuguesa nas séries iniciais. Cascavel: Assoeste, 2007. (Caderno Pedagógico 02).

BRASIL. Decreto n 5.803, de 8 de junho de 2006. Dispõe sobre o Observatório da Educação, e dá outras providências. Disponível em:

<http://www.planalto.gov.br/ccivil_03/_Ato2004-2006/2006/Decreto/

D5803.htm>. Acesso em: 20 jul. 2016.

BRASIL. Lei no 9394, de 20 de dezembro de 1996. Estabelece as diretrizes e bases da educação nacional. Disponível em: <http://www.planalto.gov.br/ ccivil_03/Leis/L9394.htm>. Acesso em: 23 maio 2012.

CANDAU, V. M. F. Formação de professores. Tendências atuais. In: REALI, A. M. M.R. et al. Formação de professores, tendências atuais. São Carlos: EDUFSCAR, 1996. p. 139-152.

CARVALHO, M. A.; ALONSO, M. R. M. H. Formação continuada de professores e mudança na prática pedagógica. In: ALONSO, M. (Org.). Prática docente: teoria e prática. São Paulo: Pioneira, 1999.

CASTELA, G. S. A leitura e a didatização do (hiper)texto eletrônico no ensino de espanhol como língua estrangeira (E/LE). 2009. 252 p. Tese (Doutorado) Faculdade de Letra, UFRJ, Rio de Janeiro, 2009.

COSTA-HÜBES, T. A alfabetização na história: um resgate das concepções que orientaram a prática alfabetizadora no final da década de 1970 até meados de 1980. In: SEMINÁRIO DE ESTUDOS DA LINGUAGEM, 4., SEMINÁRIO NACIONAL DE ESTUDOS DA LINGUAGEM. 200 anos da chegada da família real portuguesa: Formação de identidade(s) linguística(s), 1., 2009, Cascavel. Anais... Cascavel: UNIOESTE, 2009.

- O processo de formação continuada dos professores no Oeste do

Paraná: um resgate histórico-reflexivo da formação em Língua Portuguesa. 2008. Tese (Doutorado em Estudos da Linguagem) - Centro de Letras e Ciências Humanas, UEL, Londrina, 2008.

FARACO, C. A. Linguagem e diálogo, as ideias linguísticas do círculo de Bakhtin. São Paulo: Criar, 2003.

FREIRE, P. Pedagogia do oprimido. Rio de Janeiro: Paz e Terra, 2004.

FUZA, A. F. O conceito de leitura na Prova Brasil. 2010. Dissertação (Mestrado em Letras) - Universidade Estadual de Maringá, Maringá, 2010. 
GERALDI, J. W. (Org.). O texto na Sala de Aula. 3. ed. São Paulo: Ática, 2004. . Da redação à produção de textos. In: GERALDI, J. W.; CITELLI, B.(Coord.). Aprender e ensinar com textos de alunos. São Paulo: Cortez, 1997. . Portos de passagem. São Paulo: Martins Fontes, 1993.

KATO, M. O aprendizado da leitura. São Paulo: Martins Fontes, 1995.

KLEIMAN, A. B. Oficina de leitura: teoria \& prática. 4. ed. Campinas, SP: UNICAMP, Pontes, 1996.

KLEIMAN, A. B. O processo de aculturação pela escrita: ensino da forma ou aprendizagem da função? In: KLEIMAN, Angela B.; SIGNORINI, I. (Orgs.). $O$ ensino e a formação do professor. alfabetização de jovens e adultos. Porto Alegre: Artmed, 2000.

KOCK, I. V.; ELIAS, V. M. Ler e compreender: os sentidos do texto. 3.ed. São Paulo: Contexto, 2010.

LEFFA, V. J. Perspectivas no estudo da leitura: Texto, leitor e interação social. In: LEFFA, V. J.; PEREIRA, A. E. (Org.). O ensino da leitura e a produção textual: alternativas de renovação. Pelotas: EDUCAT, 1999.

MARCUSCHI, L. A. Processos de compreensão. In: . Produção textual, análise de gêneros e compreensão. 2.ed. São Paulo: Parábola Editorial, 2008. p. 226-281.

MENEGASSI, R. J.; ANGELO, C. M. P. Conceitos de leitura. In: MENEGASSI, R. J. (org.). Leitura e ensino - Formação de Professores EAD, 19. Maringá: EDUEM, 2005.

MENEGASSI, R. J.; FUZA, A. F.; OHUSCHI, M. C. G. Concepções de linguagem e o ensino da leitura em língua materna. Linguagem \& Ensino - UCPel, v. 14, p. 479-501, 2011.

NóvOA, A. Os professores e a sua formação. 2. ed. Lisboa: Instituto de Inovação Educacional, 1995.

PIMENTA, S. G. O estágio na formação de professores: unidade teórica e prática. 3. ed. São Paulo: Cortez, 2005.

ROJO, R. H. R. A concepção de leitor e produtor de textos nos PCNs: "Ler é melhor do que estudar". In: FREITAS, M. T. A.; COSTA, S. R. (Org.). Leitura e escrita na formação de professores. São Paulo: Musa/UFJF/INEP-COMPED, 2002.

SAVIANI, D. Perspectiva marxiana do problema subjetividadeintersubjetividade. In: DUARTE, N. (Org.). Crítica ao fetichismo da individualidade. Campinas: Autores Associados, 2004. 
SCHNEUWLY, B. Le langage écrit chez l'enfant: la production des textes informatifs et argumentatifs. Paris: Delachaux \& Niestlé, 1998.

SMITH, F. Compreendendo a leitura: uma análise psicolinguística da leitura e do aprender a ler. Porto Alegre: Artes Médicas, 1989.

SOLÉ, I. Estratégias de leitura. 6. ed. Porto Alegre: Artes Médicas, 1998.

TRAVAGLIA, L. C. Gramática e interação: uma proposta para o ensino de gramática no $1^{\circ}$ e $2^{\circ}$ graus. 6. ed. São Paulo: Cortez, 2001. 